\title{
Optimization of Fermentation Conditions of Lentinula edodes (Berk.) Pegler (Shiitake Mushroom) Mycelia as a Potential Biopesticide
}

\author{
Harjinder Kaur ${ }^{1}$, Leopold M. Nyochembeng ${ }^{1}$, Pratik Banerjee ${ }^{2}$, Ernst Cebert ${ }^{1} \&$ S. R. Mentreddy ${ }^{1}$ \\ ${ }^{1}$ College of Agricultural, Life, \& Natural Sciences, Alabama A\&M University, Huntsville, USA \\ ${ }^{2}$ School of Public Health, The University of Memphis, Memphis, USA \\ Correspondence: Leopold M. Nyochembeng, College of Agricultural, Life \& Natural Sciences, Huntsville, \\ Alabama, 35762, USA. Tel: 1-256-372-4218. E-mail: leopold.nyochembeng@aamu.edu
}

$\begin{array}{ll}\text { Received: January 15, } 2019 & \text { Accepted: June 4, } 2019 \quad \text { Online Published: August 15, } 2019 \\ \text { doi:10.5539/jas.v11n13p1 } & \text { URL: https://doi.org/10.5539/jas.v11n13p1 }\end{array}$

The research is financed by College of Agricultural, Life and Natural Sciences (CALNS), Alabama A\&M University.

\begin{abstract}
The shiitake mushroom [Lentinula edodes (Berk.) Pegler], is a new source of biopesticide against bacterial spot of tomato having similar efficacy as that of traditional antibiotics in vitro. The culture-filtrates of fifteen commercially available $L$. edodes strains were screened for antibacterial activity against Erwinia amylovora (Ea) and Xanthomonas campestris pv. vesicatoria $(\mathrm{Xcv})$, based on fermentation time and carbon source for minimum oxalic acid production. Two different carbon sources, glucose and sucrose for fifteen and 30 days were used for fermentation. The detection and quantification of oxalic acid in culture filtrates were performed by using HPLC. Most of the L. edodes strains inhibited the growth of Ea (13 out of 15) and Xcv (14 out of 15) with similar efficacy as that of the control treatment of $100 \mu \mathrm{g} \mathrm{mL}^{-1}$ streptomycin sulfate. Two of the L. edodes strains, ATCC 38164 and ATCC 28760 released the least amount of oxalic acid in both carbon sources, but did not differ from each other significantly. The concentration of oxalic acid in glucose medium was generally lower than that in sucrose medium, while strains ATCC 20635 and ATCC 38167 released the highest and similar concentrations in both carbon sources. This study provides preliminary evidence that $L$. edodes strains may be potential alternatives to streptomycin and copper compounds as a source of metabolites against bacterial spot of tomato and fire blight of apple [Malus $\times$ domestica $($ Borkh.)] and merits further investigation.
\end{abstract}

Keywords: Erwinia amylovora, Lentinula edodes, tomato, Xanthomonas campestris, oxalic acid

\section{Introduction}

Sustainable agricultural systems particularly in plant protection of organic production systems face numerous challenges due to lack of robust organic pesticides as summarized by Crowder and Harwood (2014). The management of bacterial plant diseases, such as, bacterial spot of tomato (Solanum lycopersicum L.) and fire blight of apple [Malus $\times$ domestica (Borkh.)] and pear (Pyrus communis L.) caused by Xanthomonas campestris pv. vesicatoria $(\mathrm{Xcv})$ and Erwinia amylovora $(\mathrm{Ea})$, respectively is even more challenging (McManus \& Stockwell, 2000; Potnis et al. 2015). Numerous authors (McManus \& Stockwell, 2000; McManus, 2014; Potnis et al., 2015; Griffin et al., 2017) have addressed the issue that, farmers can no longer rely on the traditional control measures involving the use of copper compounds and streptomycin for these plant diseases. In the United States, streptomycin had been permitted to manage fire blight of apple and pear as a standard control measure in conventional and organic orchards (McManus \& Stockwell, 2000; Anonymous, 2012). But residual streptomycin detected in apple fruits (Mayerhofer et al., 2009) and streptomycin resistant genes, discovered in E. amylovora isolates from shoots, blossom and rootstock in apple orchards (Tancos et al., 2016), indicate the possibibily of horizontal gene transfer to the non-target micro-organisms. While there is no direct evidence that the use of streptomycin in agriculture introduces antibiotic resistance to non-taget microorganisms or human pathogens through the food chain (McManus, 2014), the overall concerns about antibiotic resistance need to be addressed (Mayerhofer et al., 2009; Shade, 2013; McManus, 2014; Singer \& Williams-Nguyen, 2014). Therefore, research 
focusing on developing alternatives to streptomycin for use in organic apple and pear production is of high priority (Anonymous, 2012).

Research efforts focused on streptomycin alternatives involve the use of non-pathogenic bacteria, plant or compost extracts, essential oils, antibiotics, synthetic chemical compounds, bacteriophages, and nano-materials (Griffin et al., 2017). Of the many products, one of the most effective against bacterial spot and fire blight is acibenzolar-S-methyl (ASM) (Johnson et al., 2016; Griffin et al., 2017). However, ASM is not as effective as standard control measures using copper compounds and streptomycin sulfate against the bacterial spot of tomato and fire blight of apple, respectively (Johnson et al., 2016; Griffin et al., 2017).

Numerous studies (Binaco, 1981; Abate \& Abraham, 1994; Pacumbaba et al., 1999; Hatvani, 2001; Bender et al., 2003; Kitzberger et al., 2007; Enman et al., 2008; Bisen et al., 2010; Reis et al., 2012, Giavis, 2014) have explored shiitake mushroom's pharmaceutical and antimicrobial potential and separated antibacterial compounds like pentathiadecane, cortinellin, desoxyhypnophilin, ergosterol, lentinan, lenthionine, oxalic acid, eritadenine, protocatechuic acid, and p-hydroxy benzoic acid. Although $L$. edodes has been well documented for its antimicrobial properties, there are few reports (Pacumbaba et al., 1999; Tolaini et al., 2010; Silva et al., 2013; Wang et al., 2013; Kaur et al., 2016) on its potential biopesticidal applications.

In our previous study (Kaur et al., 2016), findings indicated that $L$. edodes culture-filtrate suppressed bacterial spot symptoms in tomato with the same efficacy as that of $100 \mu \mathrm{g} \mathrm{mL} \mathrm{m}^{-1}$ streptomycin sulfate in vitro, however, oxalic acid phytotoxicity symptoms were observed under natural conditions. According to Heleno et al. (2015), the most common secondary metabolites in L. edodes fruiting bodies are sugars (fructose, mannitol and trehalose), fatty acids (palmitic acid, stearic acid, oleic acid, linoleic acid and $\alpha$-linolenic acid), phenolic compounds (protocatechuic acid, p-hydroxybenzoic acid and cinnamic acid), and organic acids (fumaric acid, citric acid, malic acid, quinic acid, and oxalic acid). Oxalic acid, a toxic organic acid is one of the most common fungal virulence factors which causes phytotoxicity in plants (Cessna et al., 2000; Williams et al., 2011; Kaur et al., 2016).

The concentration of fungal metabolites such as oxalic acid in the fermentation medium varied with the type of carbon source and time (Ishikawa et al., 2001; Hassegawa et al., 2005; Mandal \& Banerjee, 2005). In this study, we report the antibacterial activity of the culture-filtrate from various strains of L.edodes against Xcv, Ea, and optimize fermentation conditions with an appropriate carbon source for the least oxalic acid production.

\section{Materials \& Methods}

\subsection{Lentinula edodes Strains and Fermentation}

The shiitake mushroom strains of L. edodes, American Type Culture Collection (ATCC) \# 20546, 20635, 24462, $28760,36558,38164,38165,38166,38167,38169,38172,38173,44744,48858$ and 56004 were purchased from ATCC (ATCC, Rockville, MD, USA). Lentinula edodes mycelia were grown and fermented using the same procedure (except time and carbon source) as in our previous study (Kaur et al., 2016). Lentinula. edodes mycelia-cultures, from American Type Culture Collection (ATCC) \# 38169 used by Kaur et al. (2016), were fermented for 15 days in glucose and sucrose carbon sources. Since oxalic acid concentrations in glucose and sucrose were similar, culture-filtrates fermented for 30 days in sucrose carbon source from fourteen more $L$. edodes strains were screened for their antibacterial activity against Xcv and Ea cells in vitro. A new carbon source as glucose and fermentation time of 15 days were included in the fermentation for this study. All fermentations were carried out by using three biological replicates of each $L$. edodes strain. After fermentation, culture-filtrates were processed (filtered through sterile Whatman filter sheets followed by $0.45 \mu \mathrm{m}$ sterile syringe filtration, stored at $-80^{\circ} \mathrm{C}$ ).

\subsection{Bacterial Phytopathogens}

Xanthomonas campestris pv. vesicatoria (Xcv) and Erwinia amylovora (Ea) cells were locally isolated and maintained in pure cultures on agar plates as described in a previous study (Kaur et al., 2016). The plant pathogenicity assays for Xcv and Ea were performed on tomato plants and pear detached leaves, respectively as per Koch's postulates (isolation of an organism from diseased plant tissue, infection of a healthy plant and re-isolation from infected plant tissue).

\subsection{Antibacterial Assays}

The antibacterial assays were conducted in three biological replicates of freshly prepared inocula of Xcv and Ea. All $L$.edodes culture filtrates were tested for their antibacterial activity on a bacterial concentration of $10^{8}$ colony forming units (cfu). Microbial cell population for the assays was determined using optical density $\left(\mathrm{OD}_{625}\right)$ and spread plating (serial dilutions) methods. The bactericidal activity of culture-filtrates was compared to $100 \mu \mathrm{g}$ 
$\mathrm{mL}^{-1}$ streptomycin sulfate which is the concentration used in commercial and organic pome fruit orchards (Johnson \& Temple, 2013) as a positive control and bacterial cell suspension as a negative control. Please refer to our previous study (Kaur et al., 2016) for detailed methodology.

\subsection{Oxalic Acid Detection and Quantification}

The oxalic acid content analysis was carried out by modifying the method developed by Tormo and Izco (2004). The oxalic acid separation was achieved by Varian Prostar HPLC system equipped with a 335 Ultraviolet-Visible (UV-VIS) Photodiode detector, Prostar 410 autosampler, reverse phase c 18 column (Pecosil $5 \mathrm{~cm}$ length, $5 \mathrm{~mm}$ internal diameter), and a Prostar 240 quaternary pump. The mobile phase was $1 \%(\mathrm{v} / \mathrm{v})$ acetonitrile (Thermo Fisher Scientific, Waltham, MA, USA) in $20 \mathrm{mM}$ of the sodium phosphate buffer adjusted to $2.2 \mathrm{pH}$ with phosphoric acid (prepared in de-ionized double-distilled water filtered through a $0.45 \mu \mathrm{m}$ nylon membrane). The solvent was re-filtered after preparation. A standard oxalic acid stock solution of $2000 \mathrm{mg} \mathrm{mL}^{-1}$ was prepared by dissolving pure oxalic acid (Sigma Chemical Company, St. Louis, MO, USA), in double-deionized distilled-water and filtered through a $0.45 \mu \mathrm{m}$ nylon membrane. The oxalic acid calibration curve (Figure A1) was developed by plotting the chromatogram area from six concentrations $\left(100-600 \mu \mathrm{g} \mathrm{mL}^{-1}\right)$ in triplicates with duplicate injections. The mobile phase flow rate was $1.5 \mathrm{~mL} \mathrm{~min}^{-1}$. The injection volume of $100 \mu \mathrm{L}$ was run for 10 min with two min equilibration time. An ambient column temperature was maintained through the analysis. Oxalic acid was detected at $210 \mathrm{~nm}$ wavelength. The data were acquired and analyzed using the software LC Workstation (version 6.41 HPLC). In culture-filtrates, oxalic acid was detected and quantified (three BRs of each strain, duplicate injections) by comparing the retention time and peak areas with the standard curve.

\subsection{Statistical Analysis}

Data generated by each experiment were analyzed for statistical significance using the Statistical Analysis System (SAS ${ }^{9} 9.2$ SAS Institute Inc., Cary, NC, USA) software. Analysis of Variance (ANOVA) and General Linear Model (GLM) procedures of SAS were utilized, followed by treatment mean separation by LSD test at 5\% level of probability.

\section{Results}

\subsection{Xanthomonas campestris pv. vesicatoria (Xcv) Inhibition}

The culture filtrates from $14 \mathrm{~L}$. edodes strains collected after $30 \mathrm{~d}$ fermentation in sucrose carbon source, inhibited the growth of $\mathrm{Xcv}$ cells with the same level of efficacy $(\mathrm{P}<0.0001)$ as that of $100 \mu \mathrm{g} \mathrm{mL}$ streptomycin sulfate (Figure 1A). 

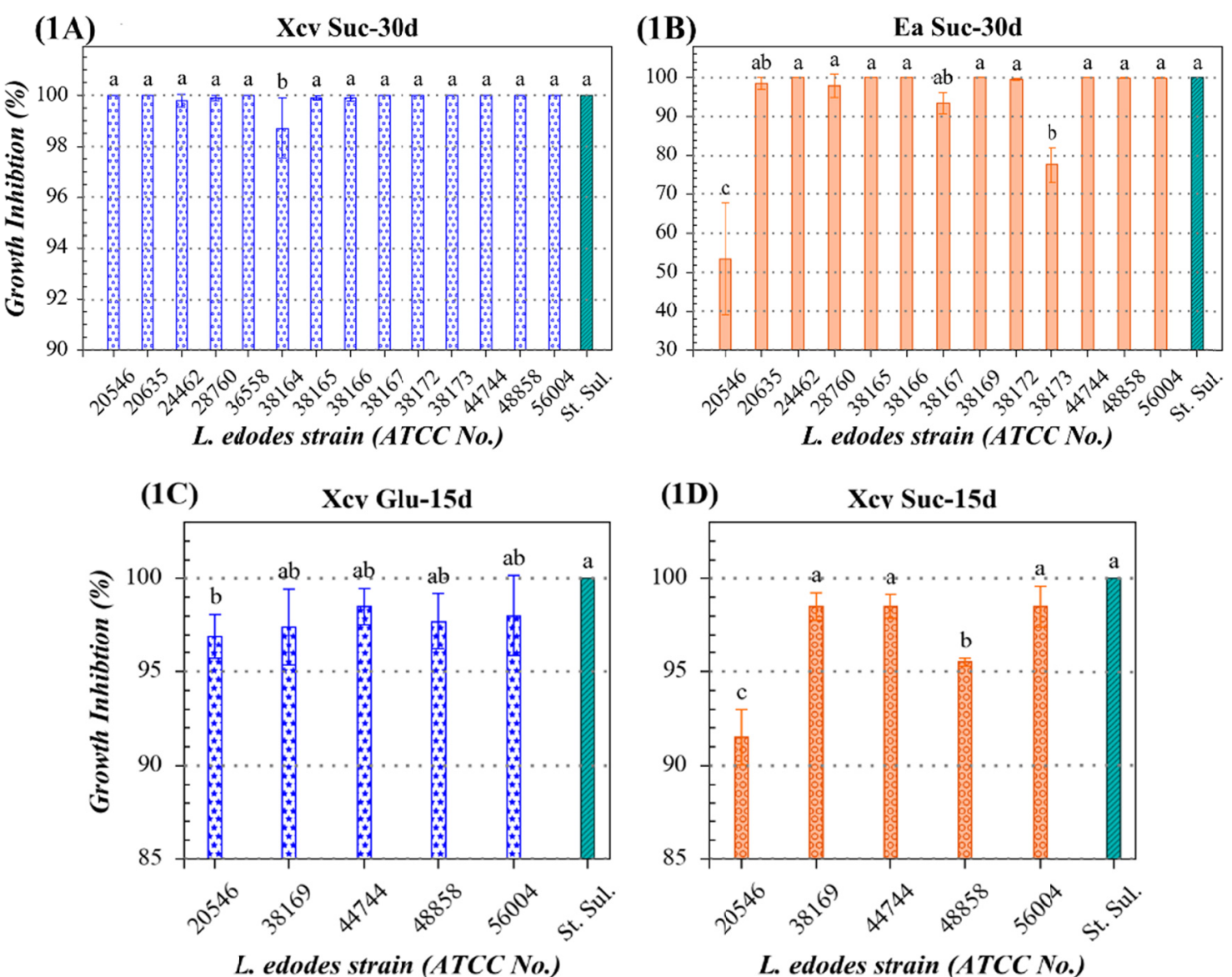

Figure 1. Antibacterial activity of $L$. edodes culture-filtrates. A, B; $30 \mathrm{~d}$ culture-filtrate fermented in sucrose sugar against Xanthomonas campestris pv. vesicatoria (Xcv) and Erwinia amylovora. (Ea), C, D; $15 \mathrm{~d}$ culture-filtrate after fermenting in glucose and sucrose sugars, respectively against Xcv. Streptomycin sulfate, $100 \mu \mathrm{g} \mathrm{mL}{ }^{-1}$ (St. Sul.) was the positive control. The bars with different letters represent significantly different growth inhibitions. The treatment means $(\mathrm{n}=3)$ were separated by LSD test $(\mathrm{P}=0.05)$. Error bars represent standard deviation.

However, only strain 38164 had a significantly $(\mathrm{P}<0.0001)$ lower growth inhibition $(98.7 \%)$ than all other strains and positive control (Figure 1A). To test if the fermentation time can be reduced further without a loss of the antibacterial activity, 15 d culture-filtrates from five L. edodes strains $(20546,38169,44744,48858$, and 56004, having similar and significantly different oxalic acid concentrations, (Table A1) were tested against Xcv cells (Figures 1C and 1D). The culture-filtrates from L. edodes strains, 38169, 44744, 48858 and 56004, collected after fermenting $(15 \mathrm{~d})$ in the glucose carbon source, inhibited Xcv growth with the same efficacy as that of $100 \%$ in streptomycin sulfate (Figure 1C). The Xcv growth inhibition by L.edodes culture-filtrates (fermented in sucrose) from strains 38169, 44744, and 56004 (98.5\% each) was also similar to that of streptomycin sulfate (Figure 1D), whereas, L.edodes culture-filtrate of strain 20546 had a significantly $(\mathrm{P}=$ 0.0001) lower antibacterial activity than streptomycin sulfate in both sugars (Figures $1 \mathrm{C}$ and 1D). 


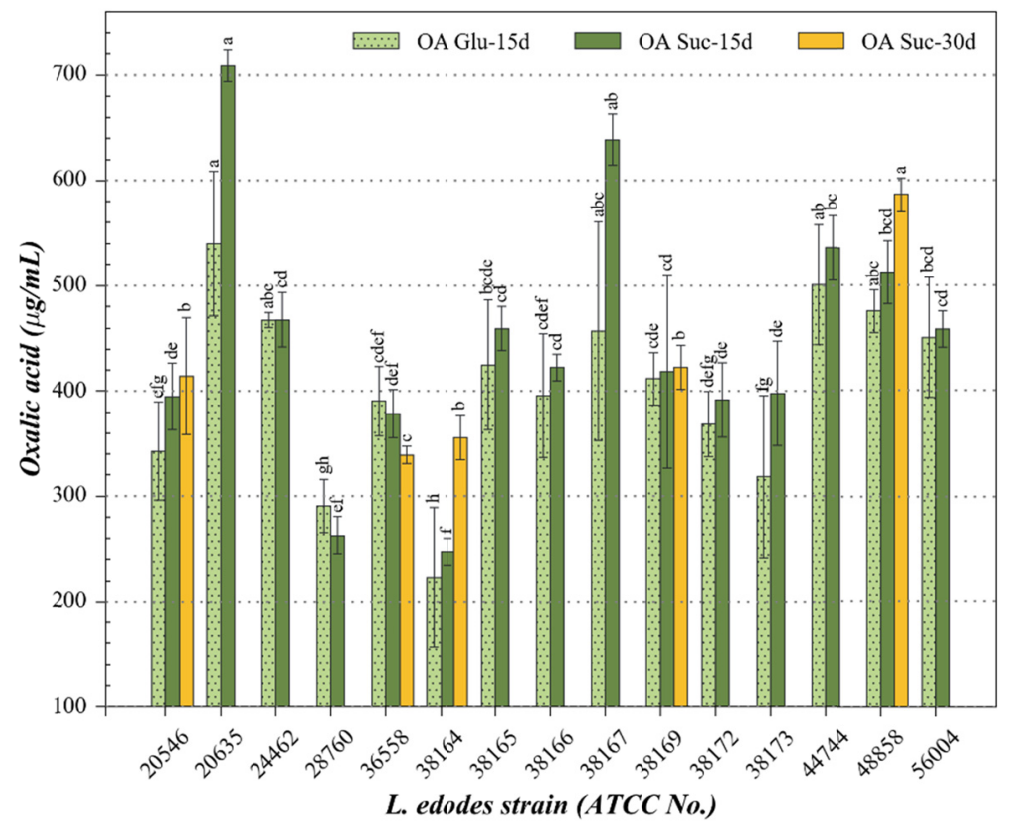

Figure 2. The oxalic acid concentrations in L edodes culture-filtrates $(n=3)$ after fermenting for $15 \mathrm{~d}$ in glucose (OA Glu-15d), sucrose (OA Suc-15d), and $30 \mathrm{~d}$ in sucrose (OA Suc-30d) carbon sources were separated by the

LSD test at $\mathrm{P}=0.05$. The error bars represent standard deviation.

\subsection{Inhibition of Erwinia amylovora (Ea)}

Culture-filtrates from $15 \mathrm{~L}$. edodes strains, collected after $30 \mathrm{~d}$ fermentation in sucrose medium were tested for antibacterial activity against Ea (Figure 1B). The growth inhibition of Ea cells by the culture-filtrate from different $L$. edodes strains varied between 53.4 and 100\% (Figure 1B). Lentinula edodes strains 36558, and 38164 were least effective against Ea. The crude $L$. edodes culture-filtrates of these strains left dense Ea colonies, which were too numerous to count. All L. edodes strains (except 20546 and 38173) inhibited Ea growth with the same efficacy as that of $100 \mu \mathrm{g} \mathrm{mL}{ }^{-1}$ streptomycin sulfate (Figure 1B). Erwinia amylovora growth inhibitions by strains $20546(53.4 \%)$ and $38173(77.5 \%)$ were significantly $(\mathrm{P}=0.0001)$ lower than that by other strains and positive control (Figure 1B).

\subsection{Fermentation Time, Carbon Source and Oxalic Acid Concentration of Lentinula edodes Strains}

Oxalic acid was eluted at $1.38 \mathrm{~min}$ (Figure A1). After $30 \mathrm{~d}$ fermentation in sucrose medium, the oxalic acid concentration in culture-filtrates of $L$. edodes strains varied between 339.1 and $586.5 \mu \mathrm{g} \mathrm{mL} \mathrm{m}^{-1}$ (Figure 2). The concentration of extracellular oxalic acid released by L.edodes strain 48858 in the fermentation medium was significantly higher than that by strains $20546,36558,38164$, and 38169 . The oxalic acid concentration in culture-filtrates from strains 20546, and 38169 was similar but was higher than strain 36558 after $30 \mathrm{~d}$ fermentation. The strains, 36558, and 38164 released significantly different $(\mathrm{P} \leq 0.05)$ concentrations of 339.1 and $355.5 \mu \mathrm{g} \mathrm{mL} \mathrm{m}^{-1}$, respectively. The oxalic acid concentration in $L$. edodes mycelial culture-filtrates collected after $15 \mathrm{~d}$ fermentation in sucrose medium varied between 247.5 and $709.1 \mu \mathrm{g} \mathrm{mL}^{-1}$ (Figure 2). When fermented in glucose carbon source, the oxalic acid concentration varied between $222.8-540.0 \mu \mathrm{g} \mathrm{mL} \mathrm{L}^{-1}$ after $15 \mathrm{~d}$ (Figure 2). Among all strains, 28760 and 38164 released the least amount of oxalic acid in both carbon sources, though they did not differ from each other significantly. Lentinula edodes strains, 20635 and 38167 released the highest and similar oxalic acid levels in the sucrose after $15 \mathrm{~d}$, whereas, mycelia from L. edodes strains 20635 and 44744 released the highest and similar concentration of oxalic acid in the glucose carbon source during $15 \mathrm{~d}$ fermentation.

\subsection{Oxalic Acid Concentration and Antibacterial Activity of L. edodes Strains}

There was no correlation (Figure A2, $\mathrm{R}^{2}=0.01$ ) between the oxalic acid concentration and antibacterial activity of the culture-filtrates. We further confirmed it by determining the minimum inhibitory concentration (Wiegand et al., 2008) of pure oxalic acid against Xcv, which was higher than the range of concentration in the culture-filtrates. Of the different oxalic acid concentrations $\left(100-5000 \mu \mathrm{g} \mathrm{mL}^{-1}\right)$ tested for antibacterial activity 
against Xcv, a bacterial lawn was observed on agar plates at $2000 \mu \mathrm{g} \mathrm{mL} L^{-1}$, whereas, total $\mathrm{Xcv}$ inhibition was observed at $2500 \mu \mathrm{g} \mathrm{mL}^{-1}$.

\section{Discussion}

Of the abundant research strategies tested to search for new and effective streptomycin alternatives to combat antimicrobial resistance in the Xcv population, ASM (acibenzolar-S-methyl) has emerged as one of the most effective products. However, its use is limited by the low efficacy as a stand-alone compound, and yield reductions in the host plants (Johnson et al., 2016; Griffin et al., 2017). It has been reported that foliar application of $L$. edodes culture-filtrates suppresses bacterial leaf spot symptoms in tomato in vitro, without adversely impacting plant height and flowering in vivo; however, oxalic acid phytotoxicity was observed on tomato foliage when tested in growth chambers (Kaur et al., 2016).

Oxalic acid in culture-filtrates of different strains of $L$ edodes fermented for different times in sucrose or glucose media varied between $222.8-709.1 \mu \mathrm{g} \mathrm{mL} \mathrm{m}^{-1}$. In general, all $L$. edodes strains released lower oxalic acid in glucose compared to sucrose carbon source. There are no previous reports on the oxalic acid concentration of $L$. edodes culture-filtrates after fermenting in different carbon sources. However, immobilized particles of Aspergillus niger have been reported to release a higher amount of oxalic acid in glucose compared to sucrose and lactose carbon sources during $7 \mathrm{~d}$ fermentation at $30{ }^{\circ} \mathrm{C}$, and $215 \mathrm{rpm}$ (Mandal \& Banerjee, 2005). The difference in extracellular oxalic acid concentration released by different $L$. edodes strains in the same medium during fermentation may be due to genetic variation among strains. Despite the variability in oxalic acid concentration, almost all of the $L$. edodes strains exhibited similar antibacterial activity against the Xcv cells. Results of this study indicate that oxalic acid concentration did not impact the antibacterial activity of the $L$. edodes culture-filtrates against Xcv. Bender et al. (2003) stated that oxalic acid concentration of $437 \mathrm{mM}$ inhibited Bacillus cereus, Streptococcus faecalis, Pseudomonas fluorescens, Alcaligenes fluorescens, Klebsiella pneumoniae, Proteus vulgaris, S. aureus and P. aeruginosa. As reported by many researchers (Binaco, 1981; Abate \& Abraham, 1994; Pacumbaba et al., 1999; Hatvani, 2001; Bender et al., 2003; Kitzberger et al., 2007; Enman et al., 2008; Bisen et al., 2010; Reis et al., 2012), numerous antibacterial compounds, including penta-thiadecane, cortinellin, desoxyhypnophilin, ergosterol, lentinan, lenthionine, eritadenine, protocatechuic acid, and p-hydroxybenzoic acid identified in Lentinus species may have contributed to the antibacterial activity of the filtrates. Our observation that antibacterial activity and toxicity of $L$. edodes culture-filtrates may not be attributed to the same compounds corroborates with the findings of Hatvani (2001).

Mycelial-culture-filtrate of several strains of $L$. edodes, tested in this study inhibited the in vitro growth of $E$. amylovora cells with the same efficacy as that of streptomycin. Pacumbaba et al., (1999) also reported similar findings of in vitro inhibition of Ea cells by $L$. edodes filtrates. Moreover, the antibacterial activity of culture-filtrates remained unaffected during and after storing for $120 \mathrm{~d}$ at $-80{ }^{\circ} \mathrm{C}$.

Although culture-filtrates were not tested on pear or apple leaves in this study, oxalic acid has been known to be a phytotoxin in model plants including tomato (Cessna et al., 2000; Williams et al., 2011; Kaur et al., 2016). In future, tomato, apple or pear plant assays it would be important to use L. edodes strains which release the least oxalic acid in the media during fermentation.

In this study, L. edodes 28760 exuded the lowest amount of oxalic acid in both sugars and exhibited Xcv and Ea growth inhibition similar to streptomycin during the initial screening of the fifteen strains. Lentinula edodes culture-filtrate may also become a potential alternative to streptomycin against fire blight of apple and pear, and other toxic chemicals in agriculture. Lentinula edodes strains, 28760, and 38164 are good candidates for further assessment as a potential biopesticide against the bacterial spot of tomato. Studies involving genomics for the genetic identification of these strains would yield beneficial results.

\section{Acknowledgements}

The College of Agricultural, Life and Natural Sciences (CALNS), Alabama A\&M University provided funds for this research. Authors specially thank Mr. Simon Ogutu, Alabama A\&M University for providing assistance in HPLC trouble shooting. Authors thank Dr. Bernhard Vogler, University of Alabama, Huntsville, AL, for technical assistance in the detection and quantification of oxalic acid.

\section{References}

Abate, D., \& Abraham, W. R. (1994). Antimicrobial metabolites from Lentinus crinitus. The Journal of Antibiotics, 47, 1348-1350. https://doi.org/10.7164/antibiotics.47.1348 
Anonymous. (2012). Formal recommendation from: National Organic Standard Board to: The National Organic Program. United States Department of Agriculture, USA. Retrieved from https://www.ams.usda. gov/sites/default/files/media/NOP\%20Crops\%20Final\%20Rec\%20Strepomycin.pdf

Bender, R. F., Lonergan, G. T., \& Baker, W. L. (2003). A case for caution in assessing the antibiotic activity of extracts of culinary-medicinal Shiitake mushroom [(Lentinula edodes (Berk.) Singer (Agaricomycetideae)]. International Journal of Medicinal Mushrooms, 31, 1-5. https://doi.org/10.1615/InterJMedicMush.v5.i1.40

Bianco, C. M., (1981). Basidiomycetes in relation to antibiosis. Antibiotic activity of mycelia and culture liquids. Bacterial Viral Immunology, 75, 274-627.

Bisen, P., Baghel, R. K., Sanodiya, B. S., Thakur, G. S., \& Prasad, G. (2010). Lentinus edodes: A macrofungus with pharmacological activities. Current Medical Chemistry, 17, 2419-2430. https://doi.org/10.2174/ 092986710791698495

Cessna, S. G., Sears, V. E., Dickman, M. B., \& Low, P. S. (2000). Oxalic acid, a pathogenicity factor for Sclerotinia sclerotiorum suppresses the oxidative burst of the host plant. The Plant Cell Online, 12, 2191-2199. https://doi.org/10.1105/tpc.12.11.2191

Crowder, D. W., \& Harwood, J. D. (2014). Promoting biological control in a rapidly changing world. Biological Control, 75, 1-7. https://doi.org/10.1016/j.biocontrol.2014.04.009

Enman, J., Hodge, D., Berglund, K. A., \& Rova, U. (2008). Production of the bioactive compound eritadenine by submerged cultivation of shiitake (Lentinula edodes) mycelia. Journal of Agricultural and Food Chemistry, 56, 2609-2612. https://doi.org/10.1021/jf800091a

Giavasis, I. (2014). Bioactive fungal polysaccharides as potential functional ingredients in food and nutraceuticals. Current Opinion in Biotechnology, 26, 162-173. https://doi.org/10.1016/j.copbio.2014. 01.010

Griffin, K., Gambley, C., Brown, P., \& Li, Y. (2017). Copper-tolerance in Pseudomonas syringae. pv. tomato and Xanthomonas spp. and the control of diseases associated with these pathogens in tomato and pepper. A systematic literature review. Crop Protection, 96, 144-150. https://doi.org/10.1016/j.cropro.2017.02.008

Hassegawa, R. H., Kasuya, M. C. M., \& Vanetti, M. C. D. (2005). Growth and antibacterial activity of Lentinula edodes in liquid media supplemented with agricultural wastes. Electronic Journal of Biotechnology, 8, 212-217. https://doi.org/10.2225/vol8-issue2-fulltext-3

Hatvani, N. (2001). Antibacterial effect of the culture filtrate of Lentinus edodes mycelium grown in submerged liquid culture. International Journal of Antimicrobial Agents, 17, 71-74. https://doi.org/10.1016/ S0924-8579(00)00311-3

Heleno, S. A., Ferreira, R. C., Antonio, A. L., Queiroz, M.-J. R., Barros, L., \& Ferreira, I. C. (2015). Nutritional value, bioactive compounds and antioxidant properties of three edible mushrooms from Poland. Food Bioscience, 11, 48-55. https://doi.org/10.1016/j.fbio.2015.04.006

Ishikawa, N. K., Kasuya, M. C. M., \& Vanetti, M. C. D. (2001). Antibacterial activity of Lentinula edodes grown in liquid medium. Brazilian Journal of Microbiology, 32, 206-210. https://doi.org/10.1590/ S1517-83822001000300008

Johnson, K., Smith, T., Temple, T., Gutierrez, E., Elkins, R., \& Castagnoli, S. (2016). Integration of acibenzolar-S-methyl with antibiotics for protection of pear and apple from fire blight caused by Erwinia amylovora. Crop Protection, 88, 149-154. https://doi.org/10.1016/j.cropro.2016.06.010

Johnson, K. B., \& Temple, T. N. (2013). Evaluation of strategies for fire blight control in organic pome fruits without antibiotics. Plant Disease, 97, 402-409. https://doi.org/10.1094/PDIS-07-12-0638-RE

Kaur, H., Nyochembeng, L. M., Mentreddy, S. R., Banerjee, P., \& Cebert, E. (2016). Assessment of the antimicrobial activity of Lentinula edodes against Xanthomonas campestris pv. vesicatoria. Crop Protection, 89, 284-288. https://doi.org/10.1016/j.cropro.2016.08.001

Kitzberger, C. S. G., Smania, A., Pedrosa, R. C., \& Ferreira, S. R. S. (2007). Antioxidant and antimicrobial activities of shiitake (Lentinula edodes) extracts obtained by organic solvents and supercritical filtrates. Journal of Food Engineering, 80, 631-638. https://doi.org/10.1016/j.jfoodeng.2006.06.013

Mandal, S. K., \& Banerjee, P. C. (2005). Submerged production of oxalic acid from glucose by immobilized Aspergillus niger. Process Biochemistry, 40, 1605-1610. https://doi.org/10.1016/j.procbio.2004.06.013 
Mayerhofer, G., Schwaiger-Nemirova, I., Kuhn, T., Girsch, L., \& Allerberger, F. (2009). Detecting streptomycin in apples from orchards treated for fire blight. Journal of Antimicrobial Chemotherapy, 63, 1076-1077. https://doi.org/10.1093/jac/dkp055

McManus, P., \& Stockwell, V. (2000). Antibiotics for plant disease control: Silver bullets or rusty sabers. APSnet Features. https://doi.org/10.1094/APSnetFeature-2000-0600

McManus, P. S. (2014). Does a drop in a bucket make a splash? Assessing the impact of antibiotic use on plants. Current Opinion in Microbiology, 19, 76-82. https://doi.org/10.1016/j.mib.2014.05.013

Pacumbaba, R., Beyl, C. A., \& Pacumbaba, Jr. R. (1999). Shiitake mycelial leachate suppresses growth of some bacterial species and symptoms of bacterial wilt of tomato and lima bean in vitro. Plant Disease, 83, 20-23. https://doi.org/10.1094/PDIS.1999.83.1.20

Potnis, N., Timilsina, S., Strayer, A., Shantharaj, D., Barak, J. D., Paret, M. L., Valled, G. E., \& Jones, J. B. (2015). Bacterial spot of tomato and pepper: Diverse Xanthomonas species with a wide variety of virulence factors posing a worldwide challenge. Molecular Plant Pathology, 16, 907-920. https://oi.org/10.1111/ mpp. 12244

Reis, F. S., Martins, A., Barros, L., \& Ferreira, I. C. (2012). Antioxidant properties and phenolic profiles of the most widely appreciated cultivated mushrooms: A comparative study between in vivo and in vitro samples. Food and Chemical Toxicology, 50, 1201-1207. https://doi.org/10.1016/j.fct.2012.02.013

Shade, A., Klimowicz, A. K., Spear, R. N., Linske, M., Donato, J. J., Hogan, C. S., ... Handlesman J. (2013). Streptomycin application has no detectable effect on bacterial community structure in apple orchard soil. Applied and Environmental Microbiology, 79, 6617-6625. https://doi.org/10.1128/AEM.02017-13

Silva, R., Pascholati, S., \& Bedendo, I. (2013). Induced resistance in tomato plants to Clavibacter michiganensis subsp. Michiganensis by Lentinula edodes and Agaricus subrufescens (syn. Agaricus brasiliensis). Journal of Plant Pathology, 95, 285-297.

Singer, R. S., \& Williams-Nguyen, J. (2014). Human health impacts of antibiotic use in agriculture: A push for improved casual inference. Current Opinion in Microbiology, 19, 1-8. https://doi.org/10.1016/ j.mib.2014.05.014

Tancos, K., Villani, S., Kuehne, S., Borejsza-Wysocka, E., Breth, D., Carol, J., ... Cox, K. (2016). Prevalence of streptomycin-resistant Erwinia amylovora in New York apple orchards. Plant Disease, 100, 802-809. https://doi.org/10.1094/PDIS-09-15-0960-RE

Tolaini, V., Zjalic, S., Reverberi, M., Fanelli, C., Fabbri, A., Del Fiore, A., ... Ricelli, A. (2010). Lentinula edodes enhances the biocontrol activity of Cryptococcus laurentii against Penicilliunm expansum contamination and patulin production in apple fruits. International Journal of Food Microbiology, 138, 243-249. https://doi.org/10.1016/j.ijfoodmicro.2010.01.044

Tormo, M., \& Izco, J. (2004). Alternative reversed-phase high performance liquid chromatography method to analyze organic acids in dairy products. Journal of Chromatography a, 1033, 305-310. https://doi.org/ 10.1016/j.chroma.2004.01.043

Wang, J., Wang, H.-Y., Xia, X.-M., Li, P. P., \& Wang, K. Y. (2013). Synergistic effect of Lentinula edodes and Pichia membranefaciens on inhibition of Penicillium expansum infections. Postharvest Biology and Technology, 81, 7-12. https://doi.org/10.1016/j.postharvbio.2013.02.002

Wiegand, I., Hilpert, K., \& Hancock, R. E. (2008). Agar and broth dilution methods to determine the minimal inhibitory concentration (MIC) of antimicrobial substances. Nature Protocols, 3, 163-175. https://doi.org/ 10.1038/nprot.2007.521

Williams, B., Kabbage, M., Kim, H. J., Britt, R., \& Dickman, M. B. (2011). Tipping the balance: Sclerotinia sclerotiorum secreted oxalic acid suppressed host defenses by manipulating the host redox environment. PLoS Pathogens, 7. https://doi.org/10.1371/journal.ppat.1002107 


\section{Appendix A}

Table A1. Oxalic acid concentration in culture-filtrates of Lentinula edodes strains after $15 \mathrm{~d}$ fermentation in glucose and sucrose carbon sources

\begin{tabular}{lll}
\hline \multirow{2}{*}{ L. edodes strain } & \multicolumn{2}{c}{ Oxalic acid $\left(\mu \mathrm{g} \mathrm{mL}^{-1}\right), 15 \mathrm{~d}$ fermentation } \\
\cline { 2 - 3 } & Glucose & Sucrose \\
\hline 20546 & $342.72 \pm 46.707 \mathrm{efg}$ & $394.66 \pm 31.731 \mathrm{de}$ \\
38169 & $411.91 \pm 24.860 \mathrm{cde}$ & $418.33 \pm 99.506 \mathrm{~cd}$ \\
44744 & $501.40 \pm 56.929 \mathrm{ab}$ & $536.12 \pm 30.495 \mathrm{bc}$ \\
48858 & $475.48 \pm 20.243 \mathrm{abc}$ & $512.70 \pm 30.460 \mathrm{bcd}$ \\
56004 & $450.23 \pm 57.181 \mathrm{bcd}$ & $458.11 \pm 17.113 \mathrm{~cd}$ \\
\hline
\end{tabular}

Note. Each datum represents mean \pm standard deviation from three values. The values sharing a similar letter are similar (LSD, $\mathrm{P}=0.05)$.

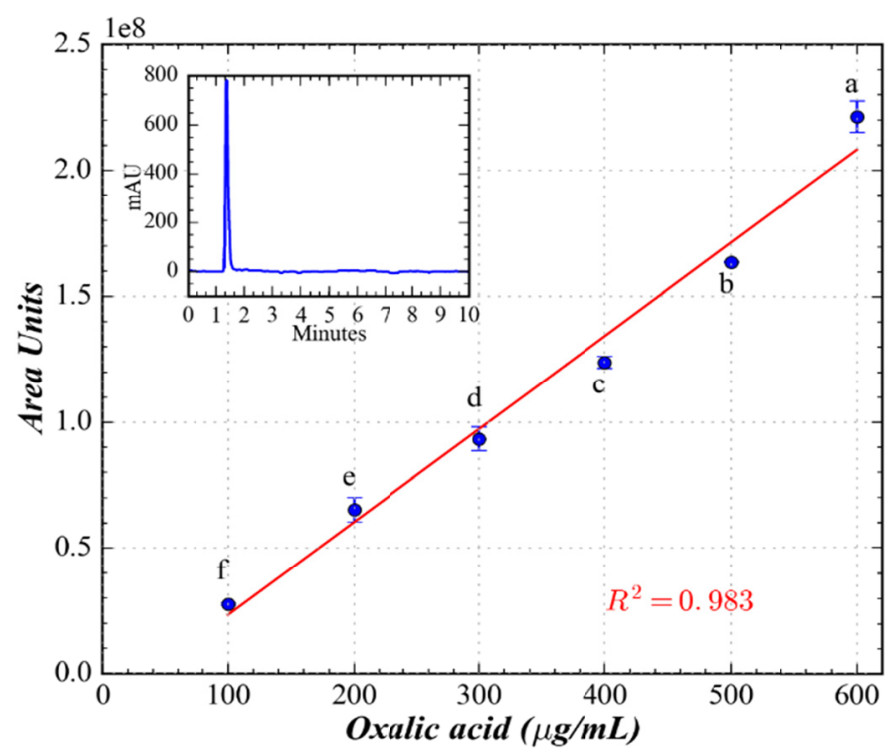

Figure A1. Oxalic acid standard curve.

The $\mathrm{X}$ and $\mathrm{Y}$-axes represent oxalic acid concentrations (100-600 $\mu \mathrm{g} \mathrm{mL} \mathrm{m}^{-1}$ ) and detector response, respectively. The standard oxalic acid chromatogram (inserted Figure) indicates that oxalic acid was eluted at $1.38 \mathrm{~min}$. The treatment means $(n=3)$ were separated by the LSD test $(P=0.05)$. The error bars represent standard deviation. 


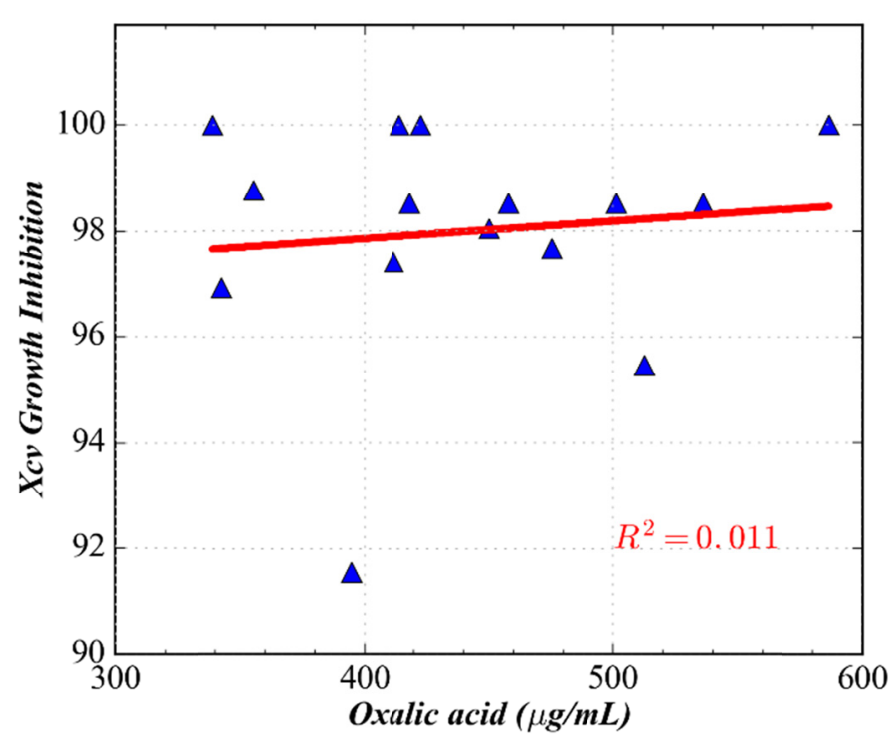

Figure A2. Oxalic acid concentration $\left(\mu \mathrm{g} \mathrm{mL}^{-1}\right)$ and growth inhibition of Xanthomonas campestris pv. vesicatoria by $L$. edodes culture-filtrates. Mean values $(\mathrm{n}=3)$ of oxalic acid and growth inhibition were plotted on $\mathrm{X}$ and $\mathrm{Y}$ axes, respectively.

\section{Copyrights}

Copyright for this article is retained by the author(s), with first publication rights granted to the journal.

This is an open-access article distributed under the terms and conditions of the Creative Commons Attribution license (http://creativecommons.org/licenses/by/4.0/). 